\title{
PROSPEK PENGOLAHAN DAUN NIPAH SEBAGAI BAHAN BAKU PEMBUNGKUS TEMBAKAU DI DESA KEUDE JRAT MANYANG KECAMATAN TANAH PASIR KABUPATEN ACEH UTARA
}

(Processing Prospect Leaves Nipah As Raw Material Packaging of Tobacco at the Village Keude Jrat Manyang in Tanah Pasir, North Aceh)

\author{
Ferdian Triady ${ }^{1}$, Irwan A. Kadir ${ }^{1}$, T. Makmur ${ }^{1 *}$ \\ ${ }^{1}$ Program Studi Peternakan, Fakultas Pertanian, Universitas Syiah Kuala
}

\begin{abstract}
Abstrak - Nipah (Nypa fruticans Wurmb.) termasuk keluarga tanaman palem merupakan tanaman hutan mangrove yang sangat mudah dijumpai di daerah pesisir serta memiliki potensi yang sangat tinggi karena setiap bagian dari tumbuhan nipah dapat dimanfaatkan. Desa Keude Jrat Manyang merupakan daerah yang telah melakukan pengolahan nipah. Tujuan penelitian ini adalah untuk mengetahui teknik pengolahan daun nipah sebagai bahan baku pembungkus tembakau, besarnya biaya dan keuntungan yang diperoleh pengrajin, dan jenis saluran pemasaran, besarnya margin dan efisiensi pemasaran daun nipah di Desa Keude Jrat Manyang Kecamatan Tanah Pasir Kabupaten Aceh Utara. Penelitian ini dilakukan dengan metode sensus. Metode analisis yang digunakan adalah metode deskriptif, metode analisis keuntungan, metode analisis margin dan efisiensi pemasaran. Hasil penelitian menunjukkan bahwa: (1) Teknik pengolahan secara sederhana berpengaruh terhadap kualitas daun nipah sebagai bahan baku pembungkus tembakau (2) Keuntungan rata-rata yang diperoleh pengrajin sebesar Rp. 1.250.872,6/Bulan, RC Rasio yang diperoleh adalah 2,1, ROI yang diperoleh adalah $110 \%$, dan $\mathrm{BEP}_{\text {Harga Jual }}$ dan $\mathrm{BEP}_{\text {Jumlah Produksi }}$ adalah $=\mathrm{Rp} .6 .650 / \mathrm{Kg}$ dan 168,07 $\mathrm{Kg} /$ Bulan; (3) Saluran pemasaran yang digunakan adalah tingkat 1, margin pemasaran dari saluran pemasaran dilokasi penelitian sebesar Rp. 9.000, serta efisiensi pemasaran daun nipah ke konsumen sebesar $39,13 \%$
\end{abstract}

Kata Kunci: Nipah, Teknik Pengolahan, Keuntungan, Saluran Pemasaran, Margin Pemasaran, Efisiensi Pemasaran

Nipah (Nypa fruticans Wurmb.), Including family palm plant is a plant that is very easy mangrove forests found in coastal areas and have a very high potential for any part of the plant can be utilized Nypa. The village of Keude Jrat Manyang is an area that has been doing the processing of Nypa. The purpose of this study was to determine the processing techniques of palm leaves as raw material for wrapping tobacco, the costs and benefits of craftsmen, and the type of marketing channels, the amount of margin and marketing efficiency of leaves nypa in the village of Keude Jrat Manyang, Tanah Pasir North Aceh. This research was conducted by census method. The analytical method used is descriptive analysis method gains, margin analysis methods and marketing efficiency. The results showed that: (1) Simple processing techniques can affect the quality of palm leaves for wrapping tobacco (2) The average profit earned craftsmen Rp. 1.250.872,6/month, RC Ratio obtained is 2.1, ROI obtained was 110\%, and BEP Price Selling and BEP Production is Rp. 6.650/Kg and 168,07 Kg/Month; (3) marketing channels used is level 1, the marketing margin of channel marketing research location Rp. 9.000, as well as the marketing efficiency of palm leaves to consumers amounting to $39.13 \%$

Keywords: Nypa, Mechanical Processing, Profit, Channel Marketing, Marketing margins, Marketing Efficiency 


\section{PENDAHULUAN}

Nipah (Nypa fruticans Wurmb.) termasuk keluarga tanaman palem (palmae) merupakan tanaman hutan mangrove yang sangat mudah dijumpai di daerah pesisir serta memiliki potensi yang sangat tinggi karena setiap bagian dari tumbuhan nipah dapat dimanfaatkan. Nipah sebagai salah satu hasil hutan non kayu hampir semua bagian tumbuhan nipah (Nypa fruticans Wurmb) memiliki manfaat. Salah satu bagian tumbuhan nipah yang telah dimanfaatkan masyarakat Indonesia yaitu daunnya. Masyarakat Indonesia memanfaatkan daun nipah sebagai pembuatan atap rumah, anyaman dinding rumah, dan berbagai kerajinan seperti tikar, topi, tas keranjang, dan media tulis. Daun nipah juga dimanfaatkan sebagai pembungkus tembakau (Mangrove Informasi Center, 2009).

Aceh merupakan salah satu provinsi yang memliki penyebaran tanaman nipah sehingga membuat wilayah tersebut memiliki potensi untuk dilakukannya usaha pengolahan tumbuhan nipah. Hal ini dibuktikan bahwa Provinsi Aceh memiliki topografi wilayah yang bervariasi yakni dataran tinggi dan dataran rendah atau pesisir sehingga tumbuhan nipah mudah untuk tumbuh. Wilayah yang memiliki pertumbuhan nipah di Provinsi Aceh yaitu Kabupaten Aceh Timur meliputi Kecamatan Simpang Ulim dan Kabupaten Aceh Utara meliputi Kecamatan Tanah Pasir dan Lapang (Nurdin, 2016).

Sebagian besar masyarakat Kecamatan Tanah Pasir sudah lama mengolah tumbuhan nipah. Salah satu wilayah yang masih mengolah pucuk nipah adalah Desa Keude Jrat Manyang. Produk yang umum diolah oleh masyarakat atau perajin tersebut adalah daun nipah. daun nipah dapat dimanfaatkan menjadi bahan baku pembuatan pembungkus tembakau sebagai pengganti kertas rokok untuk menggulung tembakau. Pada Umumnya masyarakat sekitar sering menyebutnya dengan sebutan On Lipah atau daun nipah. Rokok daun nipah adalah rokok yang dibuat dengan menggunakan tembakau yang dicampur dengan cengkeh lalu dibungkus dengan daun nipah kering.

Bahan baku yang digunakan untuk produksi daun nipah adalah pucuk nipah muda. Pucuk nipah yang digunakan ialah pucuk yang berumur kurang dari 2 bulan setelah tumbuh bakal pucuk. Setiap 3 (tiga) batang pucuk nipah dengan ukuran besar mampu menghasilkan 1 Kg lebih daun nipah. Pada umumnya, masyarakat memperoleh bahan baku dari wilayah tempat mereka tinggal. Apabila bahan baku tidak tersedia, masyarakat biasanya membeli bahan baku di desa - desa yang berpotensi tumbuhnya pohon nipah. Teknologi yang digunakan oleh masyarakat tersebut dalam proses pengolahan daun nipah kering sebagai pembungkus tembakau masih dapat dikategorikan sederhana karena teknologi ini mudah dijumpai disekitar perajin yang terdiri dari parang, pisau, tali, dan sebagainya. Sedangkan proses penjemuran daun nipah pun masih mengandalkan sinar matahari. Pada umumnya, penjemuran dilakukan selama 1 hari untuk menghilangkan kadar air yang terdapat pada daun. Setelah dikeringkan, kemudian daun nipah diasapan selama 1-2 jam sampai belerang yang digunakan habis. Tujuan dari pengasapan yaitu untuk pengawetan agar kulit daun nipah tidak mudah sobek serta mengubah warna daun menjadi lebih cerah.

Daun nipah memiliki potensi yang sangat tinggi karena pemasaran dari daun nipah itu sendiri tidak hanya dipasarkan di pasar lokal saja bahkan sudah mencapai pasar luar negeri, seperti Thailand dan Malaysia. Permintaannya pun mencapai 20 Ton perbulannya (Nurdin, 2016). Tetapi, akibat perubahan zaman modern masyarakat cenderung memilih rokok yang lebih praktis seperti rokok kretek, rokok filter, dan rokok lainnya sehingga penghisap rokok tradisional berkurang. Akibatnya, pengrajin daun nipah sedikit demi sedikit mulai 
meninggalkan tradisi nenek moyang mereka yaitu mengolah daun nipah sebagai pembungkus tembakau. Namun disisi lain, adanya permintaan pembungkus daun nipah yang sangat tinggi di pasar luar negeri sehingga sebagian besar masyarakat di Desa Keude Jrat Manyang masih melakukan pengolahan daun nipah hingga sekarang.

Adapun tujuan dari penelitian ini adalah untuk mengetahui pengaruh teknik pengolahan secara sederhana terhadap kualitas daun nipah sebagai bahan baku pembungkus tembakau, untuk mengetahui berapa biaya dan keuntungan yang diperoleh pengrajin nipah, serta untuk mengetahui aspek pemasaran daun nipah yang ditinjau dari saluran pemasaran, besarnya margin pemasaran dan efisiensi pemasaran di Desa Keude Jrat Manyang Kecamatan Tanah Pasir Kabupaten Aceh Utara.

\section{METODE PENELITIAN}

Metode yang digunakan dalam penelitian ini adalah metode sensus. Jenis data yang dikumpulkan dalam penelitian ini adalah data primer dan data sekunder. Data primer diperoleh dari dua macam teknik pengumpulan data, yaitu kuisioner dan wawancara.Data sekunder diperoleh dari studi kepustakaan. Untuk pengambilan sampel menggunakan metode sensus. Sampel pada penelitian ini adalah pengrajin yang mengolah daun nipah sebagai bahan baku pembungkus tembakau serta lembaga pemasaran.

Metode analisis yang digunakan pada penelitian ini adalah:

Pengujian Hipotesis 1, dianalisis dengan menggunakan metode analisis deskriptif kualitatif dimana memaparkan proses pengolahan daun nipah sebagai bahan baku pembungkus tembakau yang terjadi di daerah penelitian.

Pengujian Hipotesis 2, dianalisis dengan menggunakan analisis keuntungan yakni, menghitung keuntungan, RC Rasio, Revenue of Invesment, dan Break Event Point digunakan rumus sebagai berikut :

a. Keuntungan

$\Pi=\mathrm{TR}-\mathrm{TC}$. (Soehereo, 1994)

Keterangan:

$\Pi=$ Keuntungan $(\mathrm{Rp} /$ Bulan$)$

$\mathrm{TR}=$ Total Penerimaan $(\mathrm{Rp} / \mathrm{Kg})$

$\mathrm{TC}=$ Total Biaya $(\mathrm{Rp} / \mathrm{Kg})$

b. Revenue Cost (RC Rasio)

RC Rasio $=\frac{\text { Total Penerimaan }}{\text { Total Biaya }}$ ( Soekartawi, 2002)

Dengan kriteria pengambilan keputusan sebagai berikut:

- RC Ratio < 1, maka usaha pengolahan daun nipah tidak layak untuk diusahakan.

- $\quad$ RC Ratio > 1, maka usaha pengolahan daun nipah layak untuk diusahakan.

- $\quad$ RC Ratio = 1, maka usaha pengolahan daun nipah dalam titik impas atau balik modal

c. Revenue of Invesment (ROI)

ROI $=\frac{\text { Total Keuntungan }}{\text { Total Biaya Produksi }} \times 100 \%$...................(Kasmir dan Jakfar, 2003) 


\section{d. Break Event Point (BEP)}

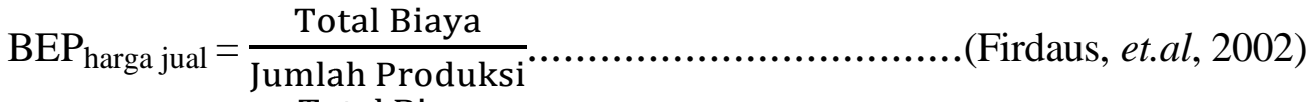

$$
\begin{aligned}
& \mathrm{BEP}_{\text {Jumlah produksi }}=\frac{\text { Total Biaya }}{\text { Harga jual }}
\end{aligned}
$$

Pengujian Hipotesis 3, dianalisis dengan menggunakan model margin pemasaran, yakni menghitung margin pemasaran dan profit margin digunakan rumus sebagai berikut :

a. Margin Pemasaran

$\mathrm{MP}=\mathrm{HB}-\mathrm{HJ}$ (Azzaino,2005)

Keterangan :

$\mathrm{MP}=$ Margin Pemasaran biji pala $(\mathrm{Rp} / \mathrm{kg})$

$\mathrm{HB}=$ Harga Beli biji pala $(\mathrm{Rp} / \mathrm{kg})$

$\mathrm{HJ}=$ Harga Jual biji pala $(\mathrm{Rp} / \mathrm{kg})$

b. $\quad$ Profit Margin

$$
\begin{aligned}
& \mathrm{PM}=\mathrm{MP}-\mathrm{BP} \text { atau } \\
& \mathrm{PM}=\frac{H J-(H P P+B P)}{H J K} \times 100 \%
\end{aligned}
$$

Keterangan :

$\mathrm{PM}=$ Profit Margin

$\mathrm{MP}=$ Margin Pemasaran $(\mathrm{Rp} / \mathrm{Kg})$

$\mathrm{BP}=$ Biaya Pemasaran $(\mathrm{Rp} / \mathrm{Kg})$

$\mathrm{HJ}=$ Harga Jual dihitung dalam $\mathrm{Rp} / \mathrm{Kg}$

HPP = Harga Pokok Penjualan atau Harga Beli

HBK = Harga Beli Konsumen

Pengujian Hipotesis 3, untuk mengetahui tingkat efisiensi pemasaran pala pada masing-masing saluran pemasaran, digunakan rumus sebagai berikut :

$$
\text { Eps }=\frac{B p}{H E} \times 100 \%
$$
...(Soekartawi, 2002)

Dimana :

Eps $=$ Efisiensi Pemasaran

$\mathrm{Bp}=$ Biaya Pemasaran

$\mathrm{HE}=$ Harga Eceran

Dengan Kriteria :

- Ep $<50 \%$ Efisien

- Ep $>50 \%$ tidak Efisien.

\section{Proses Produksi Daun Nipah}

Untuk mengetahui proses produksi pengolahan daun nipah di Deusa Keude Jrat Manyang Kecamatan Tanah Pasir Kabupaten Aceh Utara meliputi beberapa tahap yaitu:

\section{Penyediaan Bahan Baku dan Peralatan}

Mula - mula bahan baku yang digunakan dalam proses pembuatan pembungkus tembakau adalah daun nipah muda. Daun nipah diperoleh dari pucuk yang sudah berumur lebih kurang 2 bulan dengan panjang lebih kurang $2-3$ meter. Daun nipah yang muda dipilih karena teksturnya yang lentur, tidak mudah sobek dan tidak kaku, sehingga lebih mudah untuk diolah menjadi pembungkus tembakau. Pucuk muda yang dibeli oleh pengrajin adalah Rp. 1.500/Pucuk. Sarana produksi yang digunakan pengrajin dalam proses pengolahan daun nipah terdiri dari belerang, karung ukuran $50 \mathrm{Kg}$, plastik ukuran $50 \mathrm{Kg}$, tali, parang, pisau, terpal, jangka, dan timbangan. 


\section{Pemisahan}

Setelah bahan baku dan sarana produksi tersedia, langkah selanjutnya adalah pemisahan daun nipah dari pucuknya. Mula-mula daun nipah muda harus dikupas dari kulit luar pucuk agar nantinya mempermudah proses pengeringan. Setelah daun nipah dikupas dari kulit luar pucuk, maka daun nipah harus dipisahkan kembali dari tulang daun atau biasa disebut dengan batang lidi. Hal tersebut dilakukan agar mempermudah saat pengabungan dan pemotongan daun nipah. Ketelitian dan kehati-hatian dalam proses pemisahan sangat diperlukan agar saat pemisahan nantinya daun nipah tidak mudah sobek. Pekerjaan ini biasanya membutuhkan 4-5 hari yang dilakukan oleh pengrajin sebanyak 2-3 orang sedangkan peralatan yang digunakan dalam proses ini yaitu parang dan pisau.

\section{Pengeringan}

Pengeringan merupakan proses menghilangkan kadar air yang terdapat pada suatu objek. Objek yang akan dikeringkan adalah daun nipah muda yang sudah dikupas dari kulit luar pucuk dan dipisahkan dari tulang daun. Pada umumnya, proses pengeringan yang dilakukan pengrajin hanya mengandalkan bantuan sinar matahari. Pengeringan dilakukan selama sehari untuk memperoleh kualitas nipah yang baik. Ciri-ciri kualitas nipah yang baik saat pengeringan adalah daun nipah tersebut akan menggulung dengan sendirinya. Apabila proses pengeringan terlalu lama menyebabkan daun nipah berwarna kecoklatan dan menyebabkan daun nipah hangus sehingga kualitas daun nipah berkurang. Proses pengeringan yang dilakukan oleh pengrajin sangat bergantung pada cuaca. Jika cuaca panas maka daun nipah akan cepat kering, sedangkan jika cuaca mendung apalagi musim hujan maka proses pengeringan membutuh waktu yang lama bahkan sampai ditunda. Hal ini menjadi kendala dalam proses pengeringan.

\section{Pengasapan}

Proses pengasapan berguna untuk meningkatkan kualitas warna daun nipah agar menjadi warna lebih putih dan awet. Proses pengasapan dilakukan menggunakan belerang. Proses ini dilakukan dengan tujuan agar asap belerang meyerap ke dalam pori-pori nipah. Proses pengasapan harus membutuhkan kewaspadaan, apabila jarak daun nipah terlalu dekat untuk diasapakan maka yang dikhawatirkan daun nipah ikut terbakar sehingga proses pengasapan mumbutuhkan jarak sekitar 1 meter. Belerang dibeli oleh pengrajin seharga Rp. 20.000/kg. Proses pengasapan menggunakan $1 \mathrm{Kg}$ belerang mampu mengasapi $25 \mathrm{Kg}$ daun nipah kering. Mula-mula daun nipah diikat sebanyak $25 \mathrm{Kg}$, kemudian dibungkus menggunakan plastik yang berukuran $50 \mathrm{~kg}$. Daun nipah yang sudah dibungkus sebanyak 25 $\mathrm{Kg}$ kemudian digantung lalu diasap menggunakan belerang sebanyak $1 \mathrm{Kg}$. Selanjutnya belerang dibakar diatas batu cobek atau piring besi. Penggunaan batu cobek atau piring besi dikarenakan lebih awet atau tidak mudah rusak saat belerang dibakar. Proses pengasapan yang optimal dilakukan selama 1-2 jam sampai daun nipah berwarna putih kekuningan.

\section{Pemotongan}

Setelah proses pengasapan, kemudian daun nipah ditimbang sebanyak $5 \mathrm{Kg}$ dan diikat untuk diberi tanda saat pemotongan. Daun nipah diikat masing-masing $10 \mathrm{~cm}$. Lalu, daun nipah dipotong seusai tanda yang telah diberikan. Daun nipah dipotong menggunakan alat yang dinamakan jangka. Alat tersebut tidak dijual dipasar pada umumnya melainkan harus memesan kepada pengrajin besi yang berada dilokasi penelitian. Setelah proses pengasapan, kemudian daun nipah ditimbang sebanyak $5 \mathrm{Kg}$ dan diikat untuk diberi tanda saat pemotongan. Daun nipah diikat sepanjang $10 \mathrm{~cm}$. Lalu, daun nipah dipotong seusai tanda yang telah diberikan. Daun nipah dipotong menggunakan jangka. Alat tersebut tidak dijual dipasaran manapun melainkan harus memesan kepada pengrajin besi. 


\section{Penyortiran}

Setelah proses pemotongan, langkah selanjutnya adalah penyortiran. Penyortiran merupakan kegiatan yang dilakukan untuk memisahkan suatu produk yang ditinjau dari kualitas produk. Apabila kualitas produk tersebut bagus maka nilai jualnya akan tinggi, namun sebaliknya apabila kualitas produk tersebut rendah maka nilai jualnya akan rendah.

Pada penelitian ini, pengrajin tidak melakukan penyortiran melainkan mengumpul langsung hasil produksinya sehingga harga jual ditingkat pengrajin hanya sebesar Rp. 14.000/Kg. Apabila pengrajin melakukan penyortiran maka harga jual daun nipah pun akan tinggi. Kegiatan penyortiran daun nipah dilakukan oleh pedagang pengumpul, penyortiran daun nipah ditingkat pedagang pengumpul dibagi atas dua tipe yaitu, tipe I dan tipe II. Ciriciri kualitas daun nipah tipe I yaitu, daun nipah harus berwarna putih kekuningan dan tekstur kulit tebal atau tidak mudah sobek. Harga jual daun nipah tipe I yaitu, Rp. $23.000 / \mathrm{Kg}$. Sedangkan, ciri-ciri kualitas daun nipah tipe II yaitu, daun nipah berwarna kuning kecoklatan dan bertekstur tipis atau tersobek. Harga jual daun nipah tipe II sebesar Rp. 20.000/Kg. Proses penyortiran merupakan hal yang sangat penting yang harus dilakukan oleh pengrajin maupun pedagang pengumpul untuk memisahkan dan meyeragamkan daun nipah berdasarkan kualitas agar harga jual daun nipah tinggi dan meningkatkan kepuasan dari pihak konsumen.

\section{Pengemasan dan Penyimpanan}

Setelah proses penyortiran, selanjutnya daun nipah dikemas melalui dua tahap. Tahap pertama, daun nipah dibungkus menggunakan plastik yang berukuran $50 \mathrm{Kg}$. Tahap kedua, daun nipah dibungkus menggunakan kantung goni ukuran $50 \mathrm{Kg}$. Pembungkusan menggunakan kantung goni dilakukan agar kualitas nipah terjaga dan tidak mudah rusak. Setelah dikemas, proses selanjutnya dipasarkan kepada pedagang pengumpul dan pedagang pengumpul yang akan memasarkan kepada konsumen melalui eksportir yang berada di wilayah Sumatra Utara.

Berdasarkan tahapan pengolahan daun nipah diatas dapat dilihat bahwa teknik pengolahan secara sederhana dapat mempengaruhi kualitas daun nipah. Apabila dalam proses pengolahan tersebut pengrajin maupun pedagang pengumpul tidak teliti dalam mengolah daun nipah maka kualitas daun nipah akan berkurang sehingga berdampak pada harga daun nipah yang akan diterima oleh pengrajin dan pedagang pengumpul. Ciri-ciri kualitas daun nipah yang diinginkan oleh konsumen adalah daun nipah yang berwarna putih kekuningan, tekstur tebal sehingga tidak mudah sobek. Apabila daun nipah yang ditawarkan pengrajin dan pedagang pengumpul tidak sesuai dengan keinginan konsumen maka berdampak terhadap harga yang diberikan oleh konsumen. Oleh karena itu, ketelitian dalam mengolah daun nipah secara sederhana harus diperhatikan dengan baik agar kualitas tetap terjaga.

\section{Total Biaya Produksi}

Total biaya produksi merupakan keseluruhan biaya yang dikeluarkan termasuk didalamnya biaya tetap dan biaya tidak tetap. Adapun rata-rata total biaya produksi yang dikeluarkan pengrajin adalah:

Tabel 1. Rata-rata Total Biaya Produksi Pengrajin di Desa Keude Jrat Manyang Kecamatan Tanah Pasir Kabupaten Aceh Utara, 2016

\begin{tabular}{|c|l|r|}
\hline No & \multicolumn{1}{|c|}{ Uraian } & \multicolumn{2}{|c|}{ Total Biaya (Rp/Bulan) } \\
\hline 1 & Biaya Tetap: & Rp. 15.500 \\
\hline 2 & - Biaya Penyusutan alat & Rp. 765.000 \\
& Biaya Variabel & Rp. 257.385 \\
& - Biaya Bahan Baku & Rp. 80.000 \\
\hline & $\bullet$ Biaya Sarana Produksi & Rp. 1.117 .885 \\
\hline
\end{tabular}


Berdasarkan Tabel 1 dapat dilihat bahwa rata-rata total biaya produksi terdiri dari 2 biaya yaitu biaya tetap dan biaya variabel. Dimana biaya tetap yang dikeluarkan pengrajin sebesar Rp. 15.500/Bulan, sedangkan biaya variabel yang dkeluarkan sebesar Rp. 1.102.385/Bulan. Sehingga rata-rata total biaya produksi yang dikeluarkan setiap pengrajin adalah sebesar Rp. 1.117.885/Bulan.

\section{Analisis Biaya Produksi, Harga, Nilai Produksi dan Keuntungan}

Adapun produksi, harga jual, serta nilai produksi dari pengolahan daun nipah yang diperoleh pengrajin nipah dilokasi penelitian adalah:

Tabel 2. Rata-rata Produksi, Harga Jual, Nilai Produksi, dan di Desa Keude Jrat Manyang Kecamatan Tanah Pasir Kabupaten Aceh Utara, 2016

\begin{tabular}{|l|l|l|l|}
\hline No & \multicolumn{1}{|c|}{ Uraian } & \multicolumn{1}{c|}{ Satuan } & \multicolumn{1}{c|}{ Jumlah Nilai } \\
\hline 1 & Produksi Daun Nipah & Kg/Bulan & $168,07 \mathrm{Kg}$ \\
\hline 2 & Harga Jual Daun Nipah & $\mathrm{Rp} / \mathrm{Kg}$ & $\mathrm{Rp} .14 .000$ \\
\hline 3 & Nilai Produksi & Rp/Bulan & $\mathrm{Rp} .2 .353 .077$ \\
\hline
\end{tabular}

Sumber: Data Primer (diolah), 2016

Berdasarkan tabel 2 diatas, dapat dilihat bahwa rata - rata jumlah produksi nipah sebanyak 168,076 dengan harga jual Rp. 14.000, maka nilai produksi yng diperoleh pengrajin adalah sebesar Rp. 2.353.077/Bulan.

\section{Keuntungan}

Keuntungan merupakan pendapatan bersih yang diperoleh pengrajin maupun pedagang pengumpul yang diperoleh dari total penjualan daun nipah dikurangi dengan total biaya produksi atau modal dalam produksi daun nipah. Adapun hasil analisis keuntungan pada pengrajin dalam memproduksi daun nipah adalah

$$
\begin{aligned}
& \Pi=\text { TR }- \text { TC } \\
& \Pi=\text { Rp. Rp. 2.353.077 - Rp. } 1.117 .884 \\
& \Pi=\text { Rp. 1.235.193/Bulan }
\end{aligned}
$$

Berdasarkan perhitungan analisis keuntungan diatas dapat dilihat bahwa rata-rata keuntungan yang diperoleh setiap pengrajin daun nipah di Desa Keude Jrat Manyang adalah sebesar Rp. 1.235.193/Bulan.

\section{Revenue Ratio Cost $(\mathrm{R} / \mathrm{C})$}

Revenue Ratio Cost merupakan nilai yang didapat dari perbandingan antara total penerimaan dengan biaya yang dikeluarkan pada suatu usaha. Usaha yang dikatakan layak apabila $\mathrm{R} / \mathrm{C}$ ratio lebih dari 1 . Untuk mengetahui besarnya ratio pada produksi daun nipah dapat dihitung menggunakan rumus sebagai berikut:

$$
\begin{aligned}
\text { R/C Ratio } & =\frac{\text { Revenue }}{\text { Cost }} \\
\text { R/C Ratio } & =\frac{\text { Rp.2.353.077/Bulan }}{\text { Rp.1.117.884/Bulan }} \\
\text { R/C Ratio } & =2.1
\end{aligned}
$$

Berdasarkan perhitungan $\mathrm{R} / \mathrm{C}$ Ratio diatas dapat dilihat bahwa rata-rata nilai $\mathrm{R} / \mathrm{C}$ ratio sebesar 2,1. Hal ini menunjukkan bahwa setiap biaya yang dikeluarkan pengrajin sebesar Rp. 1 maka akan mampu memperoleh keuntungan sebesar Rp. 2,1. Berarti usaha produksi daun nipah layak untuk diusahakan.

\section{Return of Invesment (ROI)}

Return of Invesment merupakan analisis yang digunakan untuk mengetahui perbandingan keuntungan yang diperoleh dalam suatu usaha dengan modal yang dikeluarkan. Return of Invesment pada produksi daun nipah dapat digunakan rumus sebagai berikut: 


$$
\begin{aligned}
\text { ROI } & =\frac{\text { Total Keuntungan }}{\text { Total Biaya Produksi }} \times 100 \% \\
\text { ROI } & =\frac{\text { Rp.1.235.193/Bulan }}{\text { Rp.1.117.884/Bulan }} \times 100 \\
\text { ROI } & =110 \%
\end{aligned}
$$

Berdasarkan hasil perhitungan ROI diatas, maka dapat dilihat bahwa kemampuan pengembalian investasi pada produksi daun nipah yaitu sebesar $110 \%$. Ini berarti bahwa setiap Rp. 1, modal yang dikeluarkan pengrajin maka akan memperoleh keuntungan sebesar Rp. 110.

\section{Break Event Point (BEP)}

Break Event Point atau titik pulang pokok merupakan analisis yang digunakan untuk melihat titik balik modal yang ditinjau dari seberapa besar harga jual dan jumlah produksi usaha produksi daun nipah. Break Event Point pada usaha produksi daun nipah dapat dihitung menggunakan rumus sebsgai berikut:

$$
\begin{array}{ll}
\mathrm{BEP}_{\text {Harga Jual }} & =\frac{\text { Total Biaya Produksi }}{\text { Jumlah Produksi }} \\
\mathrm{BEP}_{\text {Harga Jual }} & =\frac{\text { Rp.1.117.884/Bulan }}{168,07 \mathrm{Kg} / \text { Bulan }} \\
\mathrm{BEP}_{\text {Harga Jual }} & =\text { Rp. } 6.651 / \mathrm{Kg}
\end{array}
$$

Berdasarkan perhitungan diatas menunjukkan bahwa Break Event Point atau titik pulang pokok dari usaha produksi daun nipah sebesar Rp. $6.651 / \mathrm{Kg}$. Ini berarti dengan harga tersebut telah mampu menutupi semua biaya produksi yang dikeluarkan pengrajin dalam usaha produksi daun nipah.

$$
\begin{array}{ll}
\mathrm{BEP}_{\text {Jumlah Produksi }} & =\frac{\text { Total Biaya Produksi }}{\text { Harga Jual }} \\
\mathrm{BEP}_{\text {Jumlah Produksi }} & =\frac{\text { Rp.1.117.884/Bulan }}{\mathrm{Rp} \cdot 6 \cdot 651} \\
\mathrm{BEP}_{\text {Jumlah Produksi }} & =168,07 \mathrm{Kg} / \mathrm{Bulan}
\end{array}
$$

Berdasarkan perhitungan diatas menunjukkan bahwa Break Event Point atau titik pulang pokok dari usaha produksi daun nipah sebesar $168,07 \mathrm{Kg} / \mathrm{Bulan}$. Ini berarti dengan jumlah produksi sebesar 168,07 Kg/Bulan telah mampu menutupi semua biaya produksi yang dikeluarkan pengrajin dalam usaha produksi daun nipah.

\section{Saluran Pemasaran}

Berdasarkan hasil penelitian yang dilakukan di Desa Keude Jrat Manyang Kecamatan Tanah Pasir Kabupaten Aceh Utara, pengrajin maupun pedagang pengumpul menggunakan saluran pemasaran 1 tingkat. Pada saluran pemasaran 1 tingkat yaitu, dimana pengrajin bertemu langsung untuk memasarkan produksi daun nipah kepada pedagang pengumpul dan pedagang pengumpul yang selanjutnya menjual kepada konsumen luar negeri melalui perantara, yaitu eksportir. Adapun skema dari saluran pemasaran daun nipah dilokasi penelitian sebagai berikut:

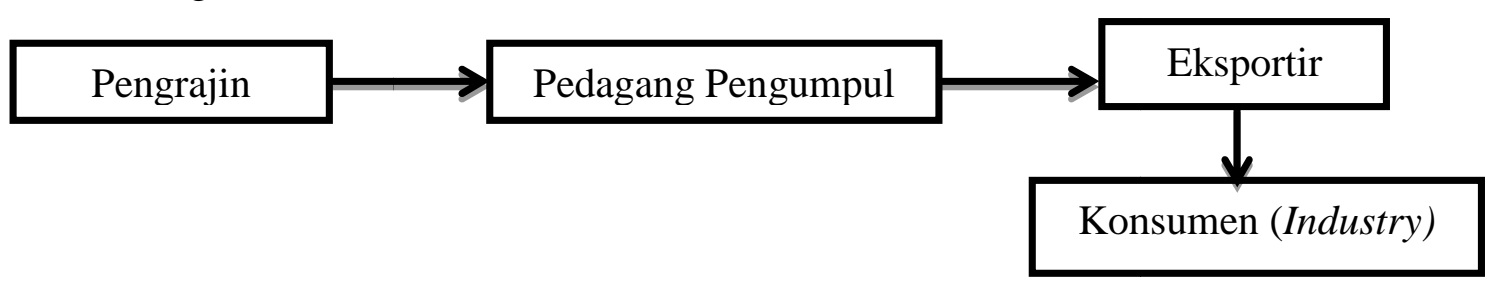

Gambar 1. Skema Saluran Pemasaran Daun Nipah di Desa Keude Jrat Manyang Kecamatan Tanah Pasir Kabupaten Aceh Utara, 2016 
Berdasarkan Gambar 1 dapat dilihat bahwa saluran pemasaran daun nipah di Desa Keude Jrat Manyang Kecamatan Tanah Pasir Kabupaten Aceh Utara dimulai dari pengrajin. Pengrajin mengolah pucuk nipah menjadi daun nipah. Kemudian daun nipah tersebut dijual kepada pedagang pengumpul dengan harga Rp. 14.000/Kg. Kemudian, daun nipah yang sudah dibeli oleh pedagang pengumpul kemudian dijual kembali kepada konsumen atau perusahaan yang berada di luar negeri melalui perantara yaitu eksportir dengan harga jual Rp. $23.000 / \mathrm{Kg}$ untuk daun nipah Tipe I dan Rp. 20.000/Kg untuk daun nipah Tipe II.

Adapun biaya pembelian, biaya penjualan, biaya ekspor, biaya transportasi, biaya tenaga kerja, serta keuntungan daun yang diperoleh oleh pedagang pengumpul sebagai berikut:

Tabel 3. Rincian Biaya Pembelian, Biaya Ekspor, Biaya Transportasi, Biaya Tenaga Kerja, Nilai Penjualan, dan Keuntungan Pedagang Pengumpul di Kecamatan Tanah Pasir, 2016

\begin{tabular}{|l|l|l|}
\hline No & Uraian Kegiatan & Nilai Biaya \\
\hline 1 & Biaya Pembelian Daun Nipah & Rp. 30.590 .000 \\
\hline 2 & Biaya Ekspor & Rp. 5.381 .000 \\
\hline 3 & Biaya Transportasi & Rp. 1.200 .000 \\
\hline 4 & Biaya Tenaga Kerja & Rp. 2.622.000 \\
\hline 5 & Nilai Penjualan Daun Nipah & Rp. 51.100.000 \\
\hline 6 & Keuntungan & Rp. 11.307 .000 \\
\hline
\end{tabular}

Sumber: Data Primer (diolah), 2016

Berdasarkan Tabel 3, dapat dilihat bahwa total biaya yang dikeluarkan pedagang pengumpul sebesar Rp.39.793.000/Bulan, sedangkan nilai penjualan dari nipah itu sendiri sebesar Rp 51.100.000/Bulan. maka dapat diperoleh keuntungan pedagang pengumpul sebesar Rp. 11.307.000/Bulan.

\section{Analisis Margin Pemasaran}

Margin pemasaran terdiri dari dua komponen yaitu biaya pemasaran dan keuntungan pemasaran. Besarnya margin pemasaran tergantung dari besarnya biaya yang dikeluarkan oleh pedagang dan pada akhirnya akan berpengaruh terhadap keuntungan yang diterima oleh pedagang tersebut. Margin pemasaran adalah selisih antara harga jual dan harga beli di setiap pelaku pemasaran pala yang terlibat dihitung dalam satuan rupiah per kilogram $(\mathrm{Rp} / \mathrm{Kg})$. Untuk mengetahui besarnya biaya pemasaran, margin pemasaran dan profit margin pada saluran pemasaran dapat dilihat pada tabel 3 .

Tabel 4. Biaya Pemasaran, Margin Pemasaran dan Profit Margin pada Saluran Pemasaran Daun Nipah ke Konsumen di Desa Keude Jrat Manyang Kecamatan Tanah Pasir Kabupaten Aceh Utara, 2016

\begin{tabular}{|c|c|c|c|}
\hline No & Lembaga dan Margin Pemasaran & Jumlah & Persentase $(\%)$ \\
\hline 1 & $\begin{array}{l}\text { Pengrajin } \\
\bullet \quad \text { Harga Jual } \\
\text { Profit Margin Pemasaran }\end{array}$ & $\begin{array}{l}\text { Rp. } 14.000 \\
\text { Rp. } 14.000\end{array}$ & 60,87 \\
\hline 2 & $\begin{array}{l}\text { Pedagang Pengumpul Kecamatan } \\
\text { - Harga Jual } \\
\text { • Biaya Pemasaran } \\
\text { Profit Margin Pemasaran }\end{array}$ & $\begin{array}{l}\text { Rp. } 23.000 \\
\text { Rp. } 4.012,7 \\
\text { Rp. } 4.987,3 \\
\end{array}$ & $\begin{array}{l}17,43 \\
21,68\end{array}$ \\
\hline 3 & $\begin{array}{l}\text { Konsumen } \\
\text { • Harga Beli }\end{array}$ & Rp.23.000 & \\
\hline 4 & Margin Pemasaran & Rp.9.000 & 100 \\
\hline
\end{tabular}


Berdasarkan Tabel 4, dapat dilihat bahwa margin pemasaran dari pemasaran daun nipah adalah sebesar Rp. 9.000. Margin pemasaran diperoleh dari hasil selisih penjualan daun nipah antara pengrajin, pedagang pengumpul dan konsumen. Adapun profit margin yang diperoleh dari setiap lembaga pemasaran yaitu, pengrajin memperoleh profit margin sebesar Rp. 14.000, pedagang pengumpul kecamatan memperoleh profit margin sebesar Rp. 4.987,3 yang diperoleh dari hasil pengurangan antara margin pemasaran dengan biaya pemasaran.

\section{Analisis Efisiensi Pemasaran}

Efisiensi pemasaran adalah perbandingan antara biaya pemasaran dengan total nilai penjualan. Kegiatan ini bertujuan untuk mengetahui keefisien nilai jual dari saluran pemasaran pengolahan daun nipah. Adapun efisiensi pemasaran daun nipah di Desa Keude Jrat Manyang sebagai berikut:

$$
\begin{aligned}
\mathrm{Ep} & =\frac{\text { Margin Pemasaran }}{\text { Nilai Produk yang dipasarkan }} \times 100 \% \\
\mathrm{Ep} & =\frac{9.000}{23.000} \times 100 \% \\
\mathrm{Ep} & =39,13 \%
\end{aligned}
$$

Berdasarkan perhitungan diatas dapat dilihat bahwa tingkat efisiensi di saluran pemasaran tingkat 1 di Desa Keude Jrat Manyang adalah sebesar 39,13\%. Hal ini membuktikan bahwa nilai jual daun nipah ditingkat pengrajin, pedagang pengumpul maupun konsumen sangat efisien. Soekartawi (2002) menyatakan bahwa apabila tingkat efisiensi lebih kecil dari $50 \%$ maka nilai pemasaran sangat efisien.

\section{KESIMPULAN DAN SARAN}

Teknik pengolahan secara sederhana dapat mempengaruhi kualitas daun nipah sebagai bahan baku pembungkus tembakau Usaha produksi daun nipah sebagai bahan baku pembungkus tembakau memperoleh keuntungan yang layak untuk diusahakan. Pemasaran olahan daun nipah masih sangat layak dan efisien untuk dipasarkan karena permintaan pasar luar negeri yang masih sangat tinggi dan tidak ada ketimpangan harga disetiap lembaga pemasaran.

Diperlukan ketelitian serta tahapan penyortiran bagi pengrajin agar kualitas daun nipah tetap terjaga sehingga berdampak kepada harga jual dari daun nipah tersebut. Dalam rangka meningkatkan keuntungan usaha produksi daun nipah sebaiknya pengrajin maupun pedagang pengumpul menambahkan modal, meningkatkan kualitas produksi serta memperluas daerah pemasaran sehingga dapat meningkatkan penjualan produksi daun nipah. Diharapkan kepada pemerintah dan pihak terkait agar lebih memperhatikan terhadap usaha ini dengan memberikan sarana dan prasarana, seperti tranportasi untuk ekspor dan pelatihan yang dapat membantu pengrajin maupun pedagang pengumpul agar lebih kreatif dalam mengolah daun nipah sehingga harga jual daun nipah itu sendiri lebih meningkat.

\section{DAFTAR PUSTAKA}

Azzaino, Z. 2005. Pengantar Tataniaga Pertanian. Jurusal Sosial Ekonomi Pertanian. IPB Bogor.

Firdaus, Y et. al. 2002. Budidaya Pemanfaatan Hasil dan Analisis Usaha serta Pemasaran. Penebar Swadaya. Jakarta. 
Kasmir dan Jakfar. 2003. Studi Kelayakan Bisnis. Kencana. Jakarta.

Mangrove Information Center. 2009. Nipah. Denpasar. Bali.

Nurdin, M interview. 2016. “Interview of Nypa”. Kecamatan Tanah Pasir, Aceh Utara.

Soeheroe, T. 1994. Matematika Ekonomi. Fakultas Ekonomi UI. Jakarta.

Soekartawi. 2002. Analisis Usahatani. UI Press. Jakarta. 